\title{
Fatores determinantes do resultado atuarial dos Regimes Próprios de Previdência Social (RPPS) municipais cearenses
}

Determining factors of the actuarial result of the municipal Special Social Security Systems (RPPS) of Ceará

\section{Francisco Wilson Ferreira da Silva ${ }^{1}$ Gleison Mendonça Diniz ${ }^{2}$}

\section{RESUMO}

A temática previdência tem se potencializado com a perspectiva de reforma estrutural quanto à metodologia de concessão de benefícios previdenciários, principalmente pela insolvência atuarial dos regimes instituídos: o geral, abarcando os empregados regidos pelas leis trabalhistas; e os Regimes Próprios de Previdência Social, abrangendo os servidores públicos estatutários. A análise de dados por meio de instrumentos estocásticos tem se evidenciado como catalisadora da identificação e correção de variáveis determinantes do resultado atuarial, permitindo o estudo da sustentabilidade requerida para as entidades previdenciárias. A partir de algumas variáveis de natureza biométrica, econômica e financeira, na perspectiva da análise de dados observados dos regimes próprios instituídos no estado do Ceará, indagou-se: quais os fatores determinantes do equilíbrio financeiro e atuarial dos RPPS cearenses? Com base na Análise de Regressão Linear e na Análise Fatorial, avaliou-se a relação entre a variável resultado atuarial versus uma ou mais variáveis explicativas, concluindo-se que a variável pensionistas é determinante da variável dependente. Os achados evidenciaram que, quanto maior o número de pensionistas beneficiários de um regime de previdência social próprio no estado do Ceará, menor

\footnotetext{
$1 \quad$ Mestre em Economia pela Universidade Federal do Ceará, graduado em Ciências Atuariais pela Universidade Federal do Ceará, técnico de controle externo lotado no Tribunal de Contas do Estado, especialista em contabilidade pública pela FA7, especialista em controle externo e auditoria pela Faculdade Tecnológica Darcy Ribeiro, especialista em controle externo pela Universidade Estadual Vale do Acaraú. Professor Pesquisador Formador I da Universidade da Integração Internacional da Lusofonia Afro-Brasileira (UNILAB). E-mail: francisco.silva@tce.ce.gov.br.

2 Pós-doutor em Administração e Controladoria (UFC), doutor em Administração de Empresas (Unifor), analista de controle externo e assessor da Vice-Presidência (TCE/CE). E-mail: gleison.diniz@tce.ce.gov.br.
} 
o resultado atuarial e maior a sua possibilidade de insolvência, isto é, a incapacidade de pagamento de benefícios previdenciários no longo prazo.

Palavras-chave: Previdência Social. Regimes próprios. Regressão. Resultado atuarial. Sustentabilidade.

\section{ABSTRACT}

The social security theme has been enhanced with the perspective of structural reform regarding the methodology of concession of social security benefits, mainly due to the actuarial insolvency of the instituted systems: the general one, encompassing employees governed by labor laws; and the Special Social Security Systems, covering statutory civil servants. Data analysis by means of stochastic instruments has proven to be a catalyst for the identification and correction of variables that determine actuarial result, allowing the study of the sustainability required for social security entities. From some variables of a biometric, economic and financial nature, in the perspective of the analysis of observed data of special systems established in the state of Ceará, the following question was asked: what are the determinants of the financial and actuarial balance of RPPS of Ceará? Based on Linear Regression Analysis and Factor Analysis, the relationship between the actuarial result variable versus one or more explanatory variables was evaluated, concluding that the pensioners variable is a determinant of the dependent variable. The findings showed that the greater the number of pensioners benefiting from a special social security system in the state of Ceará, the lower the actuarial result and the greater the possibility of insolvency, that is, the inability to pay social security benefits in the long run.

Keywords: Social Security. Special systems. Regression. Actuarial result. Sustainability. 


\section{INTRODUÇÃO}

A previdência social tem sido temática recorrente em todos os setores da administração (nacional e internacional), principalmente quando se trata da expectativa dos governantes quanto à sua capacidade de pagamento de benefícios previdenciários futuros (aposentadorias, pensões e outros benefícios).

O Le Monde (2018) publicou matéria acerca da insolvência previdenciária na França: "O déficit do sistema pode atingir entre 7,9 bilhões e 17,2 bilhões de euros em 2025". Yasarlar e Bauraktar (2019) utilizaram as razões entre o ativo e o passivo, na medição de saldos financeiros, e concluíram pela insolvência do balanço atuarial de instituições de previdência social na Turquia no período entre 1973-2013.

No Brasil, a insolvência do Regime Próprio da União e dos Estados é motivo de constantes estudos e publicação em periódicos: o portal G1, coluna Economia (2018), informou que, somados, o déficit atuarial dos RPPS federais, estaduais e municipais importam em cerca de R $\$ 6,5$ trilhões, o equivalente, quase, ao Produto Interno Bruto (PIB) projetado para o ano de 2018. Portela e Sousa (2020) concluíram que, na lógica da existência de déficit previdenciário, os governantes, em conjunto com o capital financeiro, esforçam-se em desmontar o Sistema Público de Previdência e, com ele, a estrutura dos direitos sociais fundamentais historicamente marginalizados sem que se tenha a ingerência do Estado.

$\mathrm{Na}$ administração pública municipal brasileira, dado que a Constituição Federal, em seu art. 40, permitiu aos entes federativos (União, estados, Distrito Federal e municípios) instituir Regimes Próprios de Previdência Social (RPPS), a preocupação vai além dos aspectos de solvência, incluindo, também, os processos de gestão previdenciária, de riscos e atuariais, principalmente na averiguação do quanto é determinante a relação entre as variáveis que dão suporte à apuração do resultado atuarial (a possibilidade de arrecadação de receitas e o pagamento de despesas 
previdenciárias de longo prazo): déficit ou superávit e, por consequência, a solvência dos regimes próprios de previdência no decurso do tempo (SILVA, 2014).

A Confederação Nacional dos Municípios (CNM, 2021) tem incentivado a migração dos municípios brasileiros do Regime Geral de Previdência Social (RGPS) para o RPPS sob a justificativa de eventual economia em cerca de $50 \%$ na folha de pagamento em relação à contribuição social paga ao Instituto Nacional de Seguro Social (INSS), razão pela qual 2.087 os instituíram, com uma massa de servidores públicos municipais de 7,6 milhões de trabalhadores, de acordo com dados do Ministério da Previdência Social (MPS, 2019), mas que apresentam um déficit atuarial de cerca de 50 bilhões de reais.

Na Nota Técnica $n^{\circ}$ 02/2018, o Tribunal de Contas do Estado do Piauí (TCE-PI, 2020) refutou essa justificativa, pois, na instituição e na manutenção de RPPS, o município deverá estabelecer plano de custeio e de benefícios baseados em contribuições consignadas à folha de pagamento de servidores e contribuição patronal, além dos aportes necessários ao equilíbrio financeiro e atuarial, calculados por engenheiro de risco, notadamente um atuário.

Os tribunais de contas são os órgãos de controle externo responsáveis pela fiscalização orçamentária, contábil, financeira patrimonial e operacional da Administração Pública nacional, na forma prevista nos arts. 71 e seguintes da Carta Magna Brasileira, e têm exercido o seu mister à proporção que novas metodologias vão surgindo no cenário administrativo brasileiro. Nessa perspectiva, as Cortes de Contas têm se esforçado para manter os regimes próprios de previdência social sob a óptica do controle externo.

Entretanto, tais cortes, na sua grande maioria, realizam auditoria de regularidade que, em nossa concepção, certifica a regularidade da gestão dos RPPS de forma equivocada (a partir das prestações de contas certifica o ingresso das receitas e das despesas executadas), pois não há instru- 
mentos suficientes para, elas mesmas, confeccionarem os demonstrativos do resultado da avaliação atuarial (DRRA), os fluxos de caixa (FC) e os balanços atuariais (BA) de modo a garantir o efetivo cálculo do déficit ou do superávit atuarial. Do mesmo modo, a forma de provisão das reservas matemáticas não equacionadas, que poderá ser amortizada por contribuições suplementares, de acordo com um esquema determinístico ou probabilístico a ser definido, e sem conhecimento técnico e profissional dos investimentos a serem realizados pelos RPPS para a capitalização dos recursos acumulados.

As Cortes de Contas têm buscado realizar uma fiscalização efetiva dos RPPS com base em critérios de materialidade (situação financeira e atuarial), relevância (massa de contribuintes ativos e seus potenciais beneficiários futuros) e risco (déficits atuariais e financeiros sem o devido plano de amortização e aportes necessários ao equilíbrio do RPPS) na tentativa de avaliar a sua sustentabilidade quanto aos aspectos atuariais, estruturais, financeiros, orçamentários e patrimoniais, nos termos da legislação e jurisprudência aplicáveis à matéria, e normas de auditoria, contabilidade e atuária geralmente aceitas.

Em relação aos Tribunais de Contas, Chadid (2019, p. 215) acrescenta que: "exercem a função de auxílio no cumprimento das demandas sociais e das execuções dos programas governamentais...", fazem a defesa do indivíduo, do patrimônio público e dos valores sociais e "procuram incrementar a correção de políticas públicas que possam concretizar benefícios à sociedade".

No âmbito do Tribunal de Contas da União (TCU, 2016), tem-se adotado estratégias de longo prazo para o aperfeiçoamento da regulação e da fiscalização dos RPPS por meio da análise estatística de dados e da consolidação de informações existentes nos sistemas de informação do Ministério da Previdência, combinadas com auditorias realizadas por 29 Tribunais de Contas.

$\mathrm{Na}$ esteira do TCU, os demais TCs tendem a construir outros ins- 
trumentos que lhes deem as diretrizes endógenas e quantitativas dos resultados financeiros e atuariais dos regimes próprios de previdência próprios (RPPS), pois variadas informações são encaminhadas pelos entes ao Ministério da Previdência Social (MPS), assim como são enviadas às Cortes de Contas e deverão servir de base para a avaliação de determinantes que dimensionem a adequada apuração do resultado atuarial dos entes previdenciários, assim como sejam identificadas e corrigidas hipóteses e modelos adotados, além de outras estratégias que possam evidenciar o equilíbrio financeiro e atuarial dos regimes próprios de previdência e, por ilação, a sua solvência, razão pela qual este trabalho se justifica.

No estado do Ceará, o Tribunal de Contas do Estado (TCE-CE) tem sob a sua jurisdição 64 Regimes Próprios de Previdência Social municipais instituídos e, na perspectiva de contribuir para a elaboração de novas estratégias de avaliação de políticas públicas voltadas à temática previdência, por parte dos órgãos de controle externo, de controle social (Ministério Público e controladorias, entre outros) ou pelos administradores públicos municipais, indaga-se: quais os fatores determinantes (variáveis explicativas) do resultado atuarial (equilíbrio financeiro de curto e longo prazo) dos RPPS municipais cearenses?

Para responder a essa problemática, o trabalho tem como objetivo geral identificar a relação estocástica das principais variáveis que constituem a apuração financeira e atuarial dos regimes próprios de previdência dos municípios cearenses, a partir de algumas de variáveis que compõem o resultado atuarial e a sua relação entre tais regimes. Elegeu-se a variável Resultado Atuarial como variável resposta (dependente) e outras como variáveis de composição (independentes), que poderão influenciar a variável resposta.

Uma hipótese que poderá ser determinante para influenciar a variável dependente é a população laboral (massa de contribuintes ativos do RPPS), em razão da sua participação na formação do plano de custeio dos Regimes Próprios de Previdência Social, a partir de contribuições con- 
signadas às suas folhas de pagamento. Outra, de igual importância, pode ser a acumulação de recursos financeiros garantidores do pagamento de benefícios previdenciários (ativos garantidores).

O trabalho está estruturado da seguinte forma: 1) Introdução, apresentando contexto, problemática, hipóteses, justificativa e objetivo; 2) Estado da arte: estudos da solvência dos RPPS, descrevendo pesquisas relacionadas a sustentabilidades dos RPPS à luz de variáveis biométricas, econômicas, financeiras e atuariais; 3) Metodologia, descrevendo os processos estocásticos que serão utilizados para avaliar a relação entre a variável dependente e as variáveis explicativas, assim como as semelhanças e as dissemelhanças entre os entes previdenciários; 4) Resultados, apresentando as características da pesquisa e do ambiente pesquisado, a análise dos dados e a discussão dos achados obtidos no processamento do modelo estocástico; e 5) Considerações finais, apresentando as conclusões dos autores acerca do alcance dos objetivos, confirmação da hipótese apresentada e as respostas obtidas para dirimir a problemática apontada no introito.

\section{ESTUDOS DA SOLVÊNCIA DOS REGIMES DE PREVIDÊNCIA PRÓPRIOS SOB A ÓPTICA DE VARIÁVEIS BIOMÉTRICAS, ECONÔMICAS, FINANCEIRAS E ATUARIAIS}

A Constituição Brasileira, em seu art. 40, assegurou aos servidores titulares de cargos efetivos da União, dos estados, do Distrito Federal e dos municípios, autarquias e fundações (ativos, inativos e pensionistas) o regime de previdência de caráter contributivo e solidário, mediante contribuição do respectivo ente público, desde que preservados os critérios de equilíbrio financeiro e atuarial com as seguintes características: a) previsão legal e efetiva das alíquotas de contribuição do ente federativo e da massa de servidores, determinadas pelo cálculo atuarial; b) repasse mensal e integral dos valores das contribuições à unidade gestora do regime pró- 
prio; e c) retenção, pela unidade gestora do regime, dos valores devidos pelos beneficiários (inativos e pensionistas) relativos aos benefícios cujo pagamento esteja sob sua responsabilidade.

O equilíbrio atuarial é o instrumento fundamental na institucionalização e na manutenção de um RPPS, pois traduz a incidência da totalidade de efeitos sobre o plano previdenciário em decorrência das variáveis de natureza demográfica, econômica, financeira e das relativas às políticas de recursos humanos do ente federativo, no longo prazo, utilizando-se de premissas atuariais como expectativa de vida, tábuas de mortalidade e de sobrevivência, taxa de inflação, crescimento real da remuneração, taxa de juros atuariais, entre outras.

$\mathrm{O}$ equilíbrio financeiro trata do balanceamento entre a despesa e a receita do RPPS, suficiente para o custeio do pagamento de benefícios futuros (aposentadorias, pensões etc.), em um exercício, bem como para o atendimento de contingências e despesas administrativas.

Assim, verificadas as condições básicas de sua instituição, ser sustentável é a finalidade dos RPPS de modo que, no decurso da vida e da morte das massas que o sustentam, possam ser pagos os benefícios propostos no seu planejamento (aposentadorias e pensões, entre outros), além do estabelecimento de instrumentos gerenciais, como relatórios de longo prazo das possibilidades de vida e de morte (os demonstrativos atuariais), os quais são uma estratégia para o seu equilíbrio financeiro e atuarial, e da sua organização, gestão e sustentabilidade.

Em estudos internacionais da solvência de Fundos de Pensão, como são denominados os regimes de previdência em outros países, Yaşarlar e Bayraktar (2019, p. 145) analisaram o equilíbrio atuarial do sistema previdenciário turco por meio de "estudos empíricos da análise de variáveis, modelo de regressão linear múltipla, tendo por variável dependente o resultado atuarial e como variáveis independentes dados demográficos: fertilidade, mortalidade, migração e taxas de dependência) e dados eco- 
nômicos (força de trabalho, emprego, desemprego, crescimento do PIB, inflação, crescimento dos salários e taxa de juros)". Entre os resultados, observou-se que a taxa de fertilidade aumenta a razão ativo/passivo do sistema previdenciário no curto prazo, mas esse percentual diminuiu no longo prazo, tendo como causa o aumento do número de aposentados e/ou do aumento do número de dependentes recebendo benefícios do sistema (pensionistas). Para solucionar os achados, os autores sugeriram o aumento da renda das instituições, a redução do emprego informal e o aumento do controle das instituições.

No caso de grandes massas, foi realizado um estudo por Xie et al. (2020), acerca da nova política de fertilidade da China, no equilíbrio atuarial do Fundo de Previdência para Trabalhadores Urbanos (UEBEI), por meio de modelo de mortalidade estocástico construído a partir de premissas como crescimento dos salários, tempo de contribuição e a idade de aposentadoria, taxa de contribuição, taxa anual de recomposição salarial, entre outros, e concluiu-se que o aumento da taxa de crescimento da massa salarial, decorrente de fatores sociais; o aumento da rentabilidade dos investimentos do Fundo; a postergação do direito à aposentadoria; e o aumento da taxa de contribuição ao ente são fatores determinantes para a sustentabilidade da UEBEI.

Em nível nacional Rodrigues, Nunes e Sousa (2016, p. 493) utilizaram um modelo de regressão múltipla para estimar os determinantes da seguridade social na economia da renda municipal no estado do Ceará, no exercício financeiro de 2010, tendo como variável dependente a relação entre arrecadação e despesa previdenciária, e como variáveis independentes o Produto Interno Bruto (PIB), a quantidade e proporção de idosos na população, e PIB per capita, concluindo que a previdência social cearense, "ao possibilitar a transferência de renda aos municípios mais ricos para os mais pobres", é importante mecanismo redistributivo em nível local. 
Bogoni e Fernandes (2011) buscando identificar os mecanismos de controle de riscos adotados pelos gestores dos RPPS nas atividades de investimento, em uma pesquisa descritiva, (levantamento ou survey), com abordagem quantitativa, utilizaram a Análise de Cluster para estudar o agrupamento de 58 RPPS municipais do estado do Rio Grande do Sul identificando três agrupamentos distintos, demonstrando que as melhores práticas de gestão de riscos nas atividades de investimentos são adotadas pelos RPPS dos municípios mais populosos, esses, também, com os maiores volumes de investimento.

Stolle, Kroenke e Cecon (2017) utilizando indicadores financeiros e econômicos extraídos das demonstrações contábeis dos RPPS municipais do estado de Santa Catarina (liquidez, solvência, endividamento e rentabilidade), combinados no modelo de análise multicritério TOPSIS - Technique for Order Preference by Similarity to Ideal Solution, revelaram que RPPS de menor Produto Interno Bruto (PIB) e população foram variáveis com melhor capacidade de sustentação econômico-financeira do objeto estudado.

Utilizando regressão linear em RPPS municipais do estado de Santa Catarina, José (2017, p. 102) comprovou a significativa relação entre os resultados atuariais com o porte dos municípios, salientando que:

No caso em espécie, a utilização da variável proporcional de resultado atuarial por ativo reforça a veracidade dos resultados, uma vez que exclui correlação entre o número de ativos com a dos resultados atuariais que, em geral, são majorados em um sistema previdenciário mais populoso. $\mathrm{O}$ porte, diferenciado em 2 grupos: municípios com população acima de 100 mil habitantes, e municípios com população inferior a 100 mil habitantes; comprova sua relação com o resultado atuarial.

O comportamento do Sistema de Previdência dos Servidores do Estado do Ceará (ISSEC) foi estudado por Koury (2014), por meio de uma função de reação utilizando regressão por Mínimos Quadrados Ordinários 
(MQO), concluindo, em suma, pela indicação de uma situação deficitária do instituto pesquisado, com aportes mensais de grande volume para a garantia do pagamento de benefícios previdenciários (déficit financeiro e atuarial), empregando recursos que poderiam ser utilizados em outras políticas públicas, razão pela qual o governo do estado do Ceará deveria envidar esforços para o incremento das receitas previdenciárias com o aumento de alíquotas de contribuição: ente e segurados (CEARÁ, 2019).

Por meio de função de reação fiscal, Pontes (2017) constatou o impacto negativo das contas previdenciárias na política fiscal do estado do Ceará, importante condicionante para o seu desenvolvimento, sugerindo a mensuração dos efeitos das mudanças nas regras de concessão de aposentadorias: imposição de uma idade mínima para aposentadoria superior a 60 anos de idade ou a majoração da contribuição previdenciária de ativos e inativos, minimizando os efeitos negativos que o crescimento do déficit previdenciário teria na economia local.

Estudando a solvência dos municípios de João Pessoa e de Campina Grande, da Paraíba (PB), Oliveira (2017) concluiu que foi demonstrada a capacidade de solvência do primeiro município, uma vez que foi utilizada a estratégia de segregar a massa laboral (massa "jovem" $\times$ massa "caduca"); enquanto o segundo município apresentou "situação delicada", exigindo estudos mais aprofundados para o esclarecimento da possibilidade de pagamento dos benefícios previdenciários.

Existem reiterados estudos acerca da sustentabilidade dos RPPS. Lima e Aquino (2019), na análise da carteira de investimentos de RPPS municipais, discutiram as falhas de governança e os efeitos lock-in na redução de espaço de gestores na busca de soluções transformadoras e ativas para a sua sustentabilidade financeira. Utilizam a carteira de investimentos para o pagamento de benefícios; e Caetano (2016), na simulação de reformas previdenciárias, baseadas em fórmulas de cálculo, mecanismos de indexação, alíquotas de contribuição e formas de financiamento etc. con- 
cluiu que, mesmo alterações ambiciosas de alto custo político não logram eliminar o déficit, mas tornam sua trajetória mais gerenciável.

Baeta Filho (2011) analisou o custeio, o déficit e os condicionantes de 854 municípios brasileiros com RPPS realizando testes de correlação para avaliar a correlação entre o resultado da avaliação atuarial (RESULTATR), entre 30 variáveis explicativas coletadas e regressão linear múltipla (stepwise), para avaliar os fatores condicionantes do déficit atuarial. As principais variáveis responsáveis pelo déficit foram: saldo financeiro, número de servidores ativos vinculados ao regime e valor do aporte mensal concedido pelo ente.

Santos Júnior, Azevedo e Andrade (2019), a partir de informações encaminhadas por 1.548 RPPS municipais brasileiros ao MPS, tratados por meio das Análises de Correlação e de Regressão Linear Múltipla, estimaram modelos por macrorregiões e modelo geral conjunto, concluindo que $89,02 \%$ apresentam déficit atuarial, com indícios de que a composição das variáveis preditoras em cada modelo é distinta, o que indica que características específicas em cada região influenciam com pesos diferentes no Resultado Atuarial, mas a presença das variáveis Provisão Matemática dos Benefícios a Conceder e Ativos Garantidores dos Compromissos do Plano de Benefícios se faz em todos os modelos, sendo consideradas, portanto, variáveis-chave.

No que se refere aos RPPS municipais cearenses, Silva (2014), tendo por base os demonstrativos atuariais encaminhados pelos entes ao MPS, concluiu que o déficit atuarial consolidado dos entes (63 instituídos) importou em cerca de $\mathrm{R} \$ 10$ bilhões, com ausência do registro de método de amortização efetivo que possibilitasse o aporte de recursos necessários à cobertura do déficit apurado em cada regime previdenciário, enquanto os relatórios apontavam pouco mais de 5 bilhões de déficit atuarial

Os estudos e pesquisas apresentados alhures demonstram, na prática, a busca de instrumentos tecnológicos, estatísticos e/ou econométricos que deem aos gestores dos regimes próprios de previdência e aos órgãos 
de controle externo (Tribunais de Contas) e de controle social a possibilidade de utilizá-los como parâmetros para instruírem as suas decisões de gestão e solvência, e comparações com outras variáveis determinantes na apuração dos resultados financeiros e atuariais dos regimes próprios de previdência social, assim como o planejamento de diretrizes para os processos de auditorias internas (do próprio órgão fiscalizado) ou externas (das Cortes de Contas).

\section{METODOLOGIA DA PESQUISA}

A pesquisa acerca da sustentabilidade de regimes de previdência social, em especial quanto à dependência da variável resultado atuarial (déficit / superávit) é rara, no caso de possibilidades estocásticas, e, muitas vezes, tem como escopo a busca de um padrão nas respostas em detrimento à tentativa de testar ou confirmar hipóteses.

De acordo com o conceito de Mattar (2014), esta pesquisa se classifica como exploratória quanto ao objetivo e ao grau de cristalização do problema, e descritiva quanto à natureza do relacionamento entre as variáveis, buscando a identificação daquelas que possam influir no resultado da apuração atuarial dos RPPS.

Para a sua realização, elegeram-se 63 RPPS municipais do estado do Ceará, dos 64 instituídos, uma vez que foi descartado o município de Caridade, que não encaminhou os registros de sua gestão previdenciária ao MPS desde a sua instituição, utilizando-se estatísticas e informações constantes do Banco de Dados do Ministério da Previdência Social (MPS, 2019):

a) Base de contribuição do ente federativo;

b) Demonstrativos de Informações Previdenciárias e Repasses (DIPR);

c) Demonstrativos dos Resultados da Avaliação Atuarial (DRAA) encaminhados pelos RPPS ao MPS (exercício 2018), disponibilizados no Sistema de Informações dos Regimes Públicos de Previdência Social (CadPrev).

d) Estatísticas da população coberta (servidores ativos, inativos e pensionistas); 
e) Estatísticas dos números de RPPS instituídos;

f) Valores compromissos (ativos garantidores: bancos e investimentos).

Deve-se ressaltar que o montante das observações contidas no experimento importa em 72 RPPS, incluindo-se a massa segregada ${ }^{3}$. Por exemplo: o município de Morada Nova, com alto déficit atuarial, e no intuito de minimizá-lo, separou a sua massa laboral em massa previdenciária e massa financeira. A primeira contendo os servidores com entrada mais recente no serviço público do município; enquanto a segunda, com os servidores mais antigos na administração municipal. É uma forma de amortizar o déficit atuarial calculado da massa total, embora haja controvérsias com a sua utilização, visto que, em breve período após a segregação, a massa previdenciária costuma apresentar déficit.

A pesquisa considera relevantes os dados contidos nos registros do MPS, pela significância do número de informações e das premissas adotadas para a elaboração dos demonstrativos atuariais (DRAAs): características da população de beneficiários (ativos, inativos e pensionistas); as alíquotas instituídas para a constituição de haveres, patrocinadas pelo ente e pelos servidores beneficiários (ativos e inativos); receitas e despesas previdenciárias estimadas para a composição do resultado financeiro do exercício (benefícios previdenciários de curto prazo) e resultado atuarial (benefícios previdenciários de longo prazo); e salários de contribuição e ativos (caixa e bancos) a serem capitalizados pelos institutos.

Conforme pode-se averiguar no banco de estatísticas e informações do Ministério da Previdência Social, e outras bases, inúmeras variáveis compõem os resultados de solvência, estrutura, conjuntura e avaliação aplicados aos regimes próprios de previdência: população, produto interno bruto, plano de custeio e aptidão dos gestores ao enfrentamento de riscos inerentes ao sistema previdenciários, com os mais diferentes propósitos (capitalização de recursos, amortização de déficits apurados, entre outros).

3 Segregação de massas é a separação dos membros do regime próprio em dois grupos. Esses grupos serão tratados separados quanto à gestão financeira e contábil e são divididos em dois planos: o financeiro e o previdenciário. Nota Técnica nº 03/2015/DRPSP/SPPS/MPS. Item 56. "k". Disponível em: http://sa.previdencia.gov. br/site/2016/07/NOTA-TECNICA-03-2015.pdf. 
Entretanto, o estudo está limitado à averiguação da disposição dos RPPS municipais instituídos no estado do Ceará, sem tratamento, e algumas variáveis que compõem o resultado atuarial e a sua relação entre elas, elegendo-se a variável Resultado Atuarial, como variável resposta (dependente), e apresentadas, em seguida, as variáveis de composição (independentes) que podem influenciar a variável resposta, justificadas pelas observações obtidas nos estudos realizados de Santos Júnior, Azevedo e Andrade (2019), mas sem a utilização das variáveis independentes de longo prazo: Valor Presente Atuarial (VPA) dos benefícios a conceder e concedidos, por exemplo.

Para a obtenção dos resultados, utilizar-se-á a Análise de Regressão Linear (ARL) e a Análise Fatorial (AF). A ARL tem por objetivo avaliar a relação entre a variável RESULTATR (explicada) versus uma ou mais variáveis independentes (explicativas), constantes do Quadro 1 (TABACHNICK; FIDELL, 1996 e MARTINS, 2011, p. 521), dada pelo seguinte modelo:

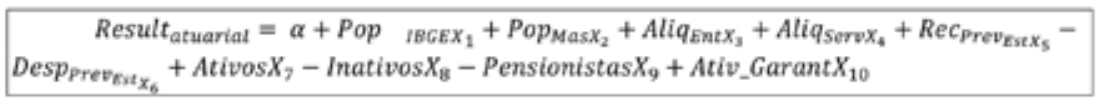

Onde: $\alpha=$ intercepto da reta; $\beta=$ inclinação da reta; e $e=$ erro aleatório de Y para a observação. 
Quadro 1 - Detalhamento das variáveis a serem utilizadas no modelo

\begin{tabular}{|c|c|c|c|c|c|}
\hline & Variável & Representação & Unidade & $\begin{array}{c}\text { Sinal } \\
\text { esperado } \\
\text { do } \\
\text { coeficiente }\end{array}$ & Fonte \\
\hline $\begin{array}{c}\text { Variável } \\
\text { Dependente }\end{array}$ & $\begin{array}{l}\text { RESULT_- }_{\text {ATUARIAL }} \\
\text { ATUA }\end{array}$ & $\begin{array}{l}\text { Resultado da projeção } \\
\text { atuarial registrada na } \\
\text { última Avaliação Atuarial } \\
\text { (AvAT) encaminhada ao } \\
\text { MPS, referente ao longo } \\
\text { prazo (35 anos, mínimo) }\end{array}$ & Reais & positivo & $\begin{array}{c}\text { MPS/Ca- } \\
\text { dPrev }\end{array}$ \\
\hline \multirow{6}{*}{$\begin{array}{c}\text { Variáveis } \\
\text { Independentes }\end{array}$} & POP_IBGE & População. Censo 2015. & Unidades & positivo & IBGE \\
\hline & POP_MAS & $\begin{array}{c}\text { Razão de dependência } \\
\text { entre o montante da } \\
\text { massa de beneficiários } \\
\text { (ATV + INAT + PENS) } \\
\text { constante na última AaAt } \\
\text { encaminhada ao MPS e a } \\
\text { variável População }\end{array}$ & Índice & positivo & Calculado \\
\hline & ALIQ_ENTE & $\begin{array}{c}\text { Percentual de contribui- } \\
\text { ção patronal vertida para } \\
\text { o RPPS registradas nas } \\
\text { AvATs encaminhadas ao } \\
\text { MPS }\end{array}$ & Índice & positivo & $\begin{array}{c}\text { MPS/Ca- } \\
\text { dPrev }\end{array}$ \\
\hline & ALIQ_SERV & $\begin{array}{c}\text { Percentual de contribui- } \\
\text { ção dos servidores vertido } \\
\text { para o RPPS registrado } \\
\text { nas AvATs encaminhadas } \\
\text { ao MPS }\end{array}$ & Índice & positivo & $\begin{array}{c}\text { MPS/Ca- } \\
\text { dPrev }\end{array}$ \\
\hline & $\begin{array}{c}\text { RES_PREV_ } \\
\text { EST }\end{array}$ & $\begin{array}{l}\text { Valor da receita projetada } \\
\text { para o } 1^{\circ} \text { exercício cons- } \\
\text { tante na AvAT encami- } \\
\text { nhada pelo RPPS ao MPS }\end{array}$ & Reais & positivo & $\begin{array}{c}\text { MPS/Ca- } \\
\text { dPrev }\end{array}$ \\
\hline & $\begin{array}{c}\text { DES_PREV_ } \\
\text { EST }\end{array}$ & $\begin{array}{c}\text { Valor da despesa proje- } \\
\text { tada para o } 1^{\circ} \text { exercício } \\
\text { constante na AvAT enca- } \\
\text { minhada pelo RPPS ao } \\
\text { MPS }\end{array}$ & Reais & negativo & $\begin{array}{c}\text { MPS/Ca- } \\
\text { dPrev }\end{array}$ \\
\hline
\end{tabular}


Quadro 1 - Detalhamento das variáveis a serem utilizadas no modelo (continuação)

\begin{tabular}{|c|c|c|c|c|c|}
\hline \multirow{5}{*}{$\begin{array}{l}\text { Variáveis Inde- } \\
\text { pendentes }\end{array}$} & Variável & Representação & Unidade & $\begin{array}{c}\text { Sinal } \\
\text { esperado } \\
\text { do } \\
\text { coeficiente }\end{array}$ & Fonte \\
\hline & ATIVOS & $\begin{array}{l}\text { Número de servidores } \\
\text { ativos beneficiários do } \\
\text { RPPS, de acordo com } \\
\text { os registros contidos na } \\
\text { última AvAt encaminhada } \\
\text { ao MPS pelo RPPS }\end{array}$ & Unidades & positivo & $\begin{array}{c}\text { MPS/Ca- } \\
\text { dPrev }\end{array}$ \\
\hline & INATIVOS & $\begin{array}{c}\text { Número de servidores } \\
\text { inativos (aposentados) } \\
\text { beneficiários do RPPS, de } \\
\text { acordo com os registros } \\
\text { contidos na última AvAt } \\
\text { encaminhada ao MPS } \\
\text { pelo RPPS }\end{array}$ & Unidades & negativo & $\begin{array}{c}\text { MPS/Ca- } \\
\text { dPrev }\end{array}$ \\
\hline & $\begin{array}{c}\text { PENSIONIS- } \\
\text { TAS }\end{array}$ & $\begin{array}{l}\text { Número de servidores } \\
\text { pensionistas beneficiários } \\
\text { do RPPS, beneficiários da } \\
\text { morte de servidor ativo } \\
\text { ou inativo, de acordo com } \\
\text { os registros contidos na } \\
\text { última AvAt encaminhada } \\
\text { ao MPS pelo RPPS }\end{array}$ & Unidades & negativo & $\begin{array}{c}\text { MPS/Ca- } \\
\text { dPrev }\end{array}$ \\
\hline & $\begin{array}{l}\text { ATIV_GA- } \\
\text { RANT }\end{array}$ & $\begin{array}{c}\text { Valor das disponibilidades } \\
\text { financeiras capitalizadas } \\
\text { pelo RPPS registradas } \\
\text { nas AvATs encaminhadas } \\
\text { ao MPS }\end{array}$ & Reais & positivo & $\begin{array}{c}\text { MPS/Ca- } \\
\text { dPrev }\end{array}$ \\
\hline
\end{tabular}

Fonte: Elaborado pelos autores (2019).

A execução do processo foi realizada por meio de dois diagnósticos: analysis de colinearity e variance inflation values, analisando variâncias e estimando parâmetros em um intervalo de significância de 95\%.

A Análise Fatorial é utilizada para a criação de novas variáveis, derivadas das originais, caso a Análise de Regressão Linear demonstre multicolinearidade entre as variáveis independentes.

Como softwares de auxílio à pesquisa, foram utilizados o Excel (versão 2012) para o registro, organização dos dados e construção de ta- 
belas, e o Statistical Analysis System (SAS) para a sua concepção das análises estatísticas.

A base de dados para a execução do processo estatístico foi nominada base_dados_RPPS_CE_2019_TCC, compilada em uma planilha Excel, contendo a lista de variáveis às quais se pode atribuir as funções da tarefa.

Na regressão linear, importante efetuar uma análise de colinearidade e multilinearidade. A primeira para verificar a existência de correlação elevada entre duas variáveis independentes, enquanto a segunda para verificar a "forte" correlação entre mais de duas variáveis independentes, pois a proporção da variação total da variável independente, explicada por X_i pode ser idêntica à proporção da variação total da variável dependente, explicada por X_(i+1), e assim por diante, demonstrando a força dessa correlação e/ou multicorrelação (COSTA, 2018).

No SAS, o diagnóstico para a detecção de multicolinearidade é realizado por meio da aba Tasks Linear Regression Collinearity Analysis, além do indicador Variance Inflation Factor (VIF), verificando a "variância de cada um dos coeficientes de regressão associados às variáveis independentes".

$$
\operatorname{Var}\left(\dot{\beta}_{i}\right)=\sigma^{2}\left(\frac{1}{1-R_{i}^{2}}\right) x \frac{1}{\sum_{j=1}^{n}\left(x_{i j}-\bar{x}_{i j}^{2}\right)}
$$

Essa variância é tanto maior quanto maior for a correlação múltipla entre X_i e as variáveis independentes e, se VIF for maior que 5, de acordo com Maroco (2003, p. 666), "estamos diante de problemas com a estimação de $\beta$ _i associado à variável X_i”. Segundo Prates (2018, p. 36), é "problemático" se assumir valor superior a 10, sendo "tolerável" até esse segmento, mas com índice de condição entre 10 e 30.

No SAS, Prates (2018) sugere que, na ocorrência de multicolinearidade de variáveis, deve-se utilizar a regressão robusta (utilização do Método dos Mínimos Quadrados Ordinários) por meio da procedure "proc 
robustreg method $=m m$ data $=$ work.base_dados_RPPS_CE_2019_TCC".

Maroco $(2003,698)$ sugere que, no caso de se obterem valores de VIF $>5$, estamos perante problemas de estimação de $\dot{\hat{\beta}}_{i}$ em razão da presença de multicolinearidade nas variáveis, devendo-se eliminar uma delas e reestimar o modelo.

$\mathrm{Na}$ execução do modelo realizou-se, também, o teste de heterocedasticidade, verificando-se a ocorrência de homocedastia (se a variância dos resíduos é constante: as mesmas nos vários grupos) e implicações no teste estatístico (ausência de confiabilidade dos resultados), utilizando-se a aba Tasks Linear Regression Heteroscedasticity Test.

Após, executa-se a regressão, selecionando-se as seguintes opções na aba Model Selection Method, com destaque na seguinte relação:

a) Full model fited (no selection), no qual o SAS seleciona a melhor opção para a construção do modelo estocástico;

b) Forward selection: o método começa apenas com a constante e adiciona, a cada passo, uma variável independente de cada vez. A primeira variável selecionada é a que apresenta maior correlação com a variável resposta;

c) Backward selection: o método incorpora todas as variáveis ao modelo e, depois, por etapas, cada uma pode ser ou não eliminada;

d) Stepwise selection: permite resolver problemas de multicolinearidade, tendo por viés a inserção no modelo da variável explicativa que apresentar o maior coeficiente de correlação com a variável dependente; $\mathrm{e}$

e) Minimum R-squared improvement: procura encontrar o que melhor se ajusta para um conjunto de dados tentando minimizar a soma dos quadrados das diferenças entre o valor estimado e os dados observados (COSTA, 2018);

Para a regressão tratada no modelo estocástico, utilizou-se no SAS o método full model, permitindo ao sistema analisar as melhores estratégias de regressão. 


\section{APRESENTAÇÃO E DISCUSSÃO DOS RESULTADOS}

Os dados para a análise do presente estudo estão contidos na Rede Mundial de Computadores ${ }^{4}$, composto por 63 regimes próprios de previdência municipais instituídos no estado do Ceará, incluindo 62 municípios e o desdobramento de 11 desses RPPS, com segregação de massa, quais sejam: Aracati, Boa Viagem, Caucaia, Eusébio, Maracanaú, Morada Nova, Ocara, Quiterianópolis, Quixadá, Quixeramobim e São Gonçalo do Amarante.

$\mathrm{Na}$ Tabela 1 são demonstradas as estatísticas descritivas das variáveis contidas no modelo econométrico.

Tabela 1 - Estatísticas das variáveis de estudo

\begin{tabular}{c|c|c|c|c}
\hline Variável & Média & Desvio-Padrão & Mínimo & Máximo \\
\hline Pop_IBGE & 93.668 & 304.350 & 3.720 & $2.591 .188,00$ \\
\hline Pop_Mas & 0,03 & 0 & 0 & 0,08 \\
\hline Aliq_ent & 12,09 & 2 & 9 & 22,00 \\
\hline Aliq_serv & 11,03 & 0 & 11 & 13,00 \\
\hline Rec_Prev_Es & $33.730 .993,70$ & 122.463 .045 & 0,00 & $831.666 .437,83$ \\
\hline Des_Prev_Es & $38.040 .707,62$ & 136.723 .985 & 0,00 & $858.207 .028,43$ \\
\hline Ativos & $1.444,42$ & 3.293 & 74 & $28.412,00$ \\
\hline Inativos & 350,42 & 1.468 & 0 & $12.540,00$ \\
\hline Pensionistas & 72,71 & 370 & 0 & $3.176,00$ \\
\hline Ativo_Garant & $33.953 .774,65$ & 82.279 .024 & 0 & $640.090 .749,02$ \\
\hline Result_atuarial & $-277.052 .331,36$ & $1.382 .729 .676,31$ & $-11.460 .129 .375,14$ & $191.403 .765,55$ \\
\hline Fon
\end{tabular}

Fonte: Elaborada pelos autores (2019).

A Análise da Regressão Linear (Tabela 2), com base em variate inflation (valores menores que 10), demonstrou que as variáveis POPMAS, ALIQCONT e DESPEST foram significativas. As demais que indicaram variate inflation foram consideradas altas, apontando problemas de multicolinearidade entre as variáveis. INAT e PENS tiveram variance inflation consideradas exageradas para o modelo adotado.

4 Cf. https://drive.google.com/file/d/1U19BBfovj4__Kk8LV3sfCOSVDOqmmVh/view?usp=sharing 
Tabela 2 - Estimativa dos parâmetros das variáveis de estudo

\begin{tabular}{|c|c|c|c|c|c|c|c|}
\hline \multicolumn{8}{|c|}{ Parameter Estimates } \\
\hline Variable & DF & $\begin{array}{l}\text { Parameter } \\
\text { Estimated }\end{array}$ & $\begin{array}{l}\text { Standard } \\
\text { Error }\end{array}$ & t Value & $\operatorname{Pr}>|\mathbf{t}|$ & $\begin{array}{c}\text { Stan- } \\
\text { dardized } \\
\text { Estimate }\end{array}$ & $\begin{array}{l}\text { Variance } \\
\text { Inflation }\end{array}$ \\
\hline Intercept & 1 & 196871396 & 787.49100 & 0.14 & 0.8915 & 0 & 0 \\
\hline $\begin{array}{l}\text { Pop }_{-} \\
\text {IBGE }\end{array}$ & 1 & -496554267 & 2535483397 & -6.31 & $<.0001$ & -1.09296 & 64.92884 \\
\hline Mas_Pop & 1 & -3713226498 & 2535483397 & -1.46 & 0.1481 & -0.03977 & 1.59339 \\
\hline Aliq_ent & 1 & -17719988 & 14476181 & -1.22 & 0.2256 & -0.03001 & 1.29902 \\
\hline Aliq_serv & 1 & 5221037 & 128467833 & 0.04 & 0.9677 & 0.00088387 & 1.02218 \\
\hline $\begin{array}{c}\text { Rec_- } \\
\text { Prev_Ex }\end{array}$ & B & 1.20821 & 1.320894 & 0.91 & 0.3639 & 0.10701 & 29.57546 \\
\hline $\begin{array}{l}\text { Des_- } \\
\text { Prev_Ex }\end{array}$ & B & -148030 & 1.33680 & -1.11 & 0.2724 & -0.14637 & 37.75905 \\
\hline Ativos & 1 & 296278 & 95085 & 3.12 & 0.0028 & 0.70561 & 110.82079 \\
\hline Inativos & 1 & -703533 & 174403 & -4.03 & 0.0002 & -0.74700 & 74.10651 \\
\hline $\begin{array}{l}\text { Pensio- } \\
\text { nistas }\end{array}$ & 1 & 381094 & 817507 & 0.47 & 0.6427 & 0.10186 & 103.17161 \\
\hline $\begin{array}{l}\text { Ativo_ } \\
\text { Garant }\end{array}$ & 1 & 2.01847 & 1.34354 & 1.50 & 0.1381 & 0.12011 & 13.81262 \\
\hline
\end{tabular}

Fonte: Elaborada pelos autores (2019).

A execução da regressão (Tabela 3) demonstrou que o modelo é estatisticamente confiante (a 95\%), mas revelou problemas de multicolinearidade nas variáveis Pop_IBGE, Rec_Prev_Es, Des_Prev_Es, Ativos, Inativos, Pens e Ativo_Garant, que apresentaram VIF maior do que $10 \mathrm{e}$, segundo o conceito de Prates (2018), inconsistentes entre os testes F e t (teste $\mathrm{F}$ estatisticamente significativo e teste t não significativo). 
Tabela 3 - Análise das variâncias de estudo

\begin{tabular}{l|c|c|c|c|c}
\hline \multicolumn{1}{c|}{ Source } & DF & $\begin{array}{c}\text { Sum of } \\
\text { Squares }\end{array}$ & Mean Square & F Value & Pr > F \\
\hline Model & 10 & $1,34 \mathrm{E}+20$ & $2,34 \mathrm{E}+25$ & 209,91 & $<.0001$ \\
\hline Error & 62 & $3,95 \mathrm{E}+18$ & $6,37 \mathrm{E}+22$ & & \\
\hline $\begin{array}{l}\text { Corrected } \\
\text { total }\end{array}$ & 72 & $1,38 \mathrm{E}+26$ & & & \\
\hline Root MSE & & 252386715 & R-Square & & 0.9713 \\
\hline Dependent Mean & -277052331 & Adj R-Sq & & 0.9667 \\
\hline Coeff Var & & -9.109 .713 & & & \\
\hline
\end{tabular}

Fonte: Elaborada pelos autores (2019).

Os testes de hipóteses não são confiáveis e podem gerar inversão do sinal dos parâmetros, como de fato ocorreu: as variáveis Mas_Pop e Alíq_ent apresentaram sinais não esperados (-).

Em razão do problema encontrado e, com base na solução proposta por Prates (2018), utilizou-se outro estimador para a regressão do modelo: Método de Regressão Robusta, com o seguinte procedimento no SAS:

proc robustreg method=mm data= work.base dados rpps ce 2019 tcc 0001;

model Result_atuarial $=$ Pop_IBGE Mas_Pop Aliq_ent Aliq_serv Rec_Prev_Ex Des_Prev_Ex Result financ Ativos Inativos Pensionistas Ativo Garant;

run;

S-Plus (1997, p. 146-147) nos dá a concepção de regressão robusta (tradução livre):

São um importante complemento às técnicas clássicas de qua-
drados mínimos, uma vez que fornecem respostas similares aos
quadrados mínimos quando existe relação linear entre variáveis
com os erros normalmente distribuídos, porém diferem signi-
ficativamente dos ajustes dos quadrados mínimos quando os
erros não satisfazem as condições de normalidade ou quando os
dados contêm outliers significantes.

A regressão robusta concebida pelo SAS, com as variáveis originais, apresentou os seguintes resultados, conforme a Tabela 4. 
Tabela 4 - Estimativa dos parâmetros das variáveis de estudo

\begin{tabular}{|c|c|c|c|c|c|c|c|}
\hline \multicolumn{8}{|c|}{ Parameter Estimates } \\
\hline \multirow{2}{*}{$\begin{array}{l}\text { Parameter } \\
\text { Intercept }\end{array}$} & \multirow{2}{*}{$\begin{array}{c}\text { DF } \\
1 \\
\end{array}$} & \multirow{2}{*}{$\begin{array}{l}\text { Estimate } \\
-3044213\end{array}$} & \multirow{2}{*}{$\begin{array}{c}\begin{array}{c}\text { Standard } \\
\text { Error }\end{array} \\
2,5874 \mathrm{E}+12 \\
\end{array}$} & \multicolumn{2}{|c|}{$\begin{array}{l}95 \% \text { Confidence } \\
\text { Limits }\end{array}$} & \multirow{2}{*}{$\begin{array}{c}\begin{array}{c}\text { Chi-S- } \\
\text { quare }\end{array} \\
0.00\end{array}$} & \multirow{2}{*}{$\begin{array}{c}\mathrm{Pr}> \\
\text { ChiSq } \\
0.9906\end{array}$} \\
\hline & & & & $5-1202 \mathrm{E} 8$ & $5.0407 \mathrm{E} 8$ & & \\
\hline $\begin{array}{l}\mathrm{Pop}_{-} \\
\mathrm{IBGE}\end{array}$ & 1 & -185986 & 212.9471 & -603.355 & 231.3827 & 0.76 & 0.3825 \\
\hline Mas_Pop & 1 & $2,201 \mathrm{E}+11$ & $5.0832 \mathrm{E} 8$ & $-7.762 \mathrm{E} 8$ & $1.2164 \mathrm{E} 9$ & 0.19 & 0.6650 \\
\hline Aliq_ent & 1 & -714290 & 2771023 & -6145394 & 4716815 & 0.07 & 0.7966 \\
\hline Aliq_serv & 1 & -2046092 & 22978738 & $-4708 \mathrm{E} 7$ & 42991407 & 0.01 & 0.9290 \\
\hline $\begin{array}{l}\operatorname{Rec}_{\text {Prev_Es }} \\
\text { Pres }\end{array}$ & 1 & 0.6333 & 0.2413 & $0-1604$ & 1.1062 & 6.89 & 0.0087 \\
\hline $\begin{array}{l}\text { Des__} \\
\text { Prev_Es }\end{array}$ & 1 & -0.4872 & 0.2448 & -0.9669 & -0.0075 & 3.96 & 0.0465 \\
\hline $\begin{array}{l}\text { Result_fi- } \\
\text { nanc }\end{array}$ & 0 & 0.0000 & . & . & . & . & . \\
\hline Ativos & 1 & 32000.65 & 19720.82 & -6651.44 & 70652.74 & 2.63 & 0.1047 \\
\hline Inativos & 1 & 5485620 & 39468.09 & -71870.4 & 82841.65 & 0.02 & 0.8895 \\
\hline Pens & 1 & -991373 & 355867.9 & $-2 \mathrm{E}+06$ & -293885 & 7.76 & 0.0053 \\
\hline $\begin{array}{l}\text { Ativo_ } \\
\text { Garant }\end{array}$ & 1 & -0.0119 & 0.2625 & -0.5264 & 0.5027 & 0.00 & 0.9640 \\
\hline Scale & 0 & 82573424 & & & & & \\
\hline
\end{tabular}

Fonte: Elaborada pelos autores (2019).

Assim, as variáveis Rec_Prev_Es (+), Desp_Prev_Es (-) e Pens (-) foram consideradas determinantes para explicar a variável dependente $R e$ sult_atuarial, com os sinais esperados representados no modelo, expresso pela fórmula a seguir:

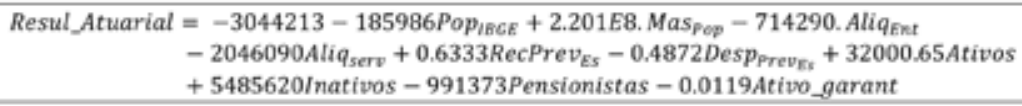

Em seguida, executou-se nova regressão com as variáveis mais representativas com a agregação das variáveis Massa $\neg$ Pop, Aliq_Ent, Aliq Serv, Rec_Prev_Es e Pens, com os resultados demonstrados na Tabela 5. 
Tabela 5 - Estimativa dos parâmetros das variáveis de estudo

\begin{tabular}{c|c|c|c|c|c|c|c}
\hline \multicolumn{7}{c}{ Parameter Estimates } \\
\hline Variable & DF & $\begin{array}{c}\text { Parameter } \\
\text { Estimated }\end{array}$ & $\begin{array}{c}\text { Standard } \\
\text { Error }\end{array}$ & t Value & Pr $>|\mathbf{t}|$ & $\begin{array}{c}\text { Stan- } \\
\text { dardized } \\
\text { Estimate }\end{array}$ & $\begin{array}{c}\text { Variance } \\
\text { Inflation }\end{array}$ \\
\hline Intercept & 1 & -387435816 & 2059444793 & -0.19 & 0.8513 & 0 & 0 \\
\hline Mas_Pop & 1 & 5494396110 & 2959472731 & 1.86 & 0.0678 & 0.05884 & 1.02321 \\
\hline Aliq_ent & 1 & -10552156 & 20243577 & -0.52 & 0.6039 & -0.01787 & 1.19734 \\
\hline Aliq_serv & 1 & 28816921 & 186042216 & 0.15 & 0.8774 & 0.00488 & 1.01041 \\
\hline $\begin{array}{c}\text { Rec_- } \\
\text { Prev_Es }\end{array}$ & 1 & 0.46636 & 0.43189 & 1.08 & 0.2841 & 0.04130 & 1.49040 \\
\hline $\begin{array}{c}\text { Pensio- } \\
\text { nistas }\end{array}$ & 1 & -3640957 & 151331 & -24.06 & $<.0001$ & -0.97312 & 1.66637 \\
\hline
\end{tabular}

Fonte: Elaborada pelos autores (2019).

Superados os problemas de heterocedasticidade, as variáveis apresentadas na Tabela 5, utilizadas no modelo estocástico, foram testadas como causa e efeito da variável dependente Result_atuarial, conforme se observa na seguinte fórmula:

Resul $_{\text {Atuarial }}=5494396110$ Mas $_{\text {Pop }}-10552156$ Aliq $_{\text {Ent }}+28816921$ Aliq $_{\text {Serv }}+$ REc $_{\text {Pre }}$ ss -3640957Pensionistas

Desse modo, os resultados indicam que quanto maiores forem as alíquotas de contribuição para o custeio do Regime Próprio de Previdência Social, e quanto menor for o número de pensionistas beneficiários do regime, maior é o resultado atuarial e, por ilação, a sua solvência e sustentabilidade.

Em razão dos problemas de heterocedasticidade encontrados no modelo inicial, e com o objetivo de identificar uma variável em especial que fosse determinante para modificar de alguma forma a variável dependente Result_atuarial, executou-se, no SAS, a análise fatorial.

Conforme demonstrado na Tabela 6 , o resultado identificou que a variável Pensionistas é correlacionada em 96,41\% da variável depen- 
dente Result_atuarial (negativamente). Assim, quanto maior o número de pensionistas beneficiários de um regime de previdência social próprio no estado do Ceará, menor o resultado atuarial e maior a sua possibilidade de insolvência, ou seja, a incapacidade de pagamento de benefícios previdenciários no longo prazo.

Tabela 6 - Matriz de Correlações. Análise Fatorial

\begin{tabular}{c|c|c|c|c|c|c}
\hline & \multicolumn{7}{c}{ Correlations } \\
\hline & $\begin{array}{c}\text { Result__ } \\
\text { atuarial }\end{array}$ & Mas_Pop & Aliq_ent & $\begin{array}{c}\text { Rec_Prev_ } \\
\text { Ex }\end{array}$ & $\begin{array}{c}\text { Aliq_ } \\
\text { serv }\end{array}$ & Pens \\
\hline Result_atuarial & 1.00000 & 0.17835 & -0.39490 & -0.52465 & 0.02147 & -0.96415 \\
\hline Mas_Pop & 0.17835 & 1.00000 & -0.01746 & -0.07946 & -0.06773 & -0.12620 \\
\hline Aliq_ent & -0.39490 & -0.01746 & 1.00000 & 0.26370 & 0.04630 & 0.39781 \\
\hline Rec_Prev_Es & -0.52465 & -0.07946 & 0.26370 & 1.00000 & -0.03177 & 0.57178 \\
\hline Aliq_serv & 0.02147 & -0.06773 & 0.04630 & -0.03177 & 1.00000 & -0.02335 \\
\hline Pensionistas & -0.96415 & -0.12620 & 0.39781 & 0.57178 & -0.02335 & 1.00000 \\
\hline
\end{tabular}

Fonte: Elaborada pelos autores (2019).

No estado do Ceará, de acordo com os registros contidos no Sistema de Informações dos Regimes Públicos de Previdência Social - CadPrev, os RPPS municipais cearenses têm em sua massa de pensionistas o montante de 5.308 pessoas, representando 5,03\% da massa laboral de servidores ativos (105.443).

A massa de pensionistas tem como origem a morte do contribuinte do regime de previdência, que deixa como herança para os seus dependentes o valor de sua remuneração mensal (no serviço público, o valor integral dos seus vencimentos), repartidos entre a companheira ou companheiro, ou aquele ou aquela com quem mantém uma união estável, e os seus dependentes: filhos naturais ou adotados ou que tenham a tutela jurídica até 24 anos de idade (se estiverem realizando curso superior).

O percentual aqui apresentado pode não parecer preocupante, mas parece ser exequível: "No Regime Geral de Previdência Social (RGPS), por exemplo, tanto nas regras atuais, como nas propostas, as alíquotas 
efetivas relativas aos aposentados e pensionistas são mais baixas do que as aplicadas aos servidores ativos, não por conta das alíquotas nominais que são as mesmas. A diferença se deve à não incidência de contribuição sobre a parcela do benefício que vai até o teto do RGPS" (PELLEGRINI, 2019, p. 27).

Em tese, o pensionista não contribui para a previdência e o dispêndio realizado é, negativamente, significante no modelo estocástico estudado.

Há de se ressaltar que trabalhos referenciados no estudo buscam a tomada de decisões a partir de processos estocásticos representativos e determinantes na apuração de resultados financeiros e atuariais dos RPPS brasileiros, mas, quando a variável preditora trata especificamente do resultado atuarial dos RPPS nacionais (estudos raros ou escassos), merece destaque o trabalho de Santos Júnior, Azevedo e Andrade (2018), que utilizaram 23 variáveis, entre elas o valor atual dos salários, o valor atual das contribuições futuras e compensações a receber, a provisão matemática dos benefícios a receber, a qualificação do gênero dos beneficiários (homem e mulher), que serviram de base para a composição das 11 variáveis que deram supedâneo à presente pesquisa.

\section{CONCLUSÕES}

A previdência, no caso de regimes próprios municipais, é uma política pública, ainda subestimada pelos edis municipais, muitas delas com resultado atuarial deficitário, o que implica a construção de estratégias de gestão previdenciária contemporâneas e atuais para a sua sustentabilidade.

A literatura tem apontado formas de manutenção da solvência dos RPPS: aportes necessários ao pagamento de benefícios previdenciários (aposentadorias, pensões e auxílios); formas de amortização do passivo atuarial por meio do parcelamento desses ao longo dos anos, dentro dos normativos legais; incremento das contribuições previdenciárias (contribuição patronal e de servidores), entre outras, baseadas em relevantes es- 
tudos estocásticos e econométricos que os validam.

As variáveis aqui estudadas indicaram que o resultado atuarial (variável dependente) foi influenciado pelas variáveis Mas_Pop, Aliq_Ente, Aliq_Serv, Rec_Prev_Est e Pensionistas, principalmente por esta última (-96,41\%). Não era o que se esperava, pois a massa de contribuintes ativos era a hipótese inicialmente apontada para justificar o resultado atuarial dos RPPS estudados, em razão de seu iminente caráter contributivo (compulsório), no custeio do regime previdenciário. Todavia, o que se pôde depreender do resultado foi outro, diverso do que se propunha: o RESUL_ATUAR é vetor. Quanto mais deficitário o regime próprio de previdência municipal, maior é a possibilidade de impacto socioeconômico e financeiro.

Em tese, o resultado da pesquisa é conclusivo para afirmar que, quanto maior o número de beneficiários (em particular o número de pensionistas), menor a alíquota de contribuição (patronal e servidor) e, quanto menor for a receita prevista (resultado financeiro), maior será o resultado atuarial deficitário e, por conseguinte, menor a possibilidade de solvência dos RPPS municipais e a manutenção da sua sustentabilidade.

Assim, os achados do modelo revelaram que é necessário que os RPPS municipais cearenses tenham o correto conhecimento do perfil dos seus segurados, inativos, pensionistas e demais beneficiários para que, dentro das premissas atuariais, financeiras, econômicas e demográficas, entre outras geralmente aceitas, e baseadas em tábuas de mortalidade, seja possível estimar o fluxo das aposentadorias e o fluxo dos falecimentos, evitando-se o impacto fiscal que, porventura, essa variável, entre as demais estudadas, possa afetar os orçamentos municipais futuros no estado do Ceará.

Os gestores devem preocupar-se, também, com a evolução da possibilidade da ocorrência do evento falecimento dos que contribuem para o RPPS, solicitando aos atuários construtores das avaliações atuariais a projeção desse evento como premissa atuarial e o seu impacto nas projeções de longo prazo nos demonstrativos das avaliações atuariais anuais (DRA- 
As), além de adotar estratégias para a minimização desse risco estrutural: aumento de alíquota de contribuição de servidores, segregação de massas (a massa mais nova poderá ter maior probabilidade de sobrevivência), entre outros instrumentos.

O objetivo geral do estudo foi atingido ao identificar a relação das principais variáveis que constituem o resultado financeiro e atuarial dos RPPS municipais cearenses, elegendo-se a variável Resultado Atuarial como variável resposta (dependente) e outras como variáveis de composição (independentes) que poderiam influenciá-la.

Como contribuição do estudo, espera-se permitir que se construam incrementos das possibilidades do poder decisório para os gestores e os beneficiários dos regimes próprios de previdência (municipais, na sua essência), principalmente no controle do fluxo de vida e de morte dos seus segurados e beneficiários, com especial atenção ao controle dos registros e ao acompanhamento dos dependentes econômicos do servidor ativo e/ ou inativo, que pode ser incrementado por censo demográfico periódico da população beneficiária do RPPS.

Outros trabalhos poderão comprovar a tese aqui ventilada, propondo aos governos, sobretudo aos municipais, e aos Tribunais de Contas, a quem cabe a responsabilidade da fiscalização orçamentária, financeira e patrimonial desses institutos, a adoção de instrumentos estatísticos e econométricos que garantam a sustentabilidade dos regimes próprios de previdência ampliando o leque de variáveis que contribuam para um resultado superavitário dos institutos previdenciários. Como sugestão para trabalhos futuros, indica-se o desenvolvimento de um modelo não linear de probabilidade, em que F seja uma distribuição de probabilidade (Modelo Probit $^{5}$ ).

$5 \quad$ Probit é abreviação de probability unit sendo atribuída a C. R Bliss, de acordo com Aldrich e Nelson (1984) em Linear probability, logit and probit models. London: Sage, 1984. 94 p. 


\section{REFERÊNCIAS}

ALDRICH, J. H.; NELSON, F. D. Linear probability, logit and probit models. London: Sage, 1984.

BAETA FILHO, L. P. Previdência no setor público: análise do custeio e déficit e suas variáveis condicionantes. 2011. 98 f. Dissertação (Mestrado) - Programa de Pós-Graduação em Administração, Faculdade Novos Horizontes, Belo Horizonte, 2011.

BEUREN, I. M. Como elaborar trabalhos monográficos em contabilidade: teoria e prática. São Paulo: Atlas, 2006.

BOGONI, N. M.; FERNANDES, F. C. Gestão de risco nas atividades de investimento dos Regimes Próprios de Previdência Social (RPPS) dos municípios do Estado do Rio Grande do Sul. Revista Eletrônica de Administração, Porto Alegre, v. 17, n. 1, p. 117-148, jan./abr. 2011. Universidade Federal do Rio Grande do Sul. Porto Alegre, Brasil. Disponível em: https:// www.scielo.br/scielo.php?pid=S1413-23112011000100005\&script=sci_ abstract\&tlng=pt. Acesso em: 30 jun. 2019.

BRASIL. [Constituição (1988)]. Constituição da República Federativa do Brasil. Brasília, DF: Presidência da República. Disponível em: http:// www.planalto.gov.br/ccivil_03/constituicao/constituicao.htm. Acesso em: 30 jun. 2019.

CAETANO, M. A.-R. Solvência fiscal de longo prazo dos Regimes Próprios de Previdência dos estados e municípios. In: Texto para discussão. Brasília: IPEA, 2016. Disponível em: http://repositorio.ipea.gov.br/bitstream/11058/6638/1/td_2195.pdf. Acesso em: 30 jun. 2019. 
CEARÁ. Lei Complementar no 167, de 27 de dezembro de 2016. Dispõe sobre a instituição do Sistema Único de Previdência Social dos Servidores Públicos Civis e Militares, dos Agentes Públicos e dos Membros de Poder do Estado do Ceará - SUPSEC e da respectiva contribuição previdenciária, extingue os benefícios previdenciários e de montepio que indica e dá outras providências. Disponível em: https://www2.al.ce.gov.br/ legislativo/ementario/lc167.htm. Acesso em: 30 jun. 2019.

CHADID, R. A função social do Tribunal de Contas no Brasil. Belo Horizonte: Fórum, 2019.

CNM. RPPS é uma solução para dívida previdenciária dos Municípios, afirma consultor. CNM, Notícias, 9 nov. 2016. Disponível em: https:// www.cnm.org.br/index.php/areastecnicas/noticias/juridico/rpps-e-uma-solucao-para-divida-previdenciaria-dos-municipios-afirma-consultor. Acesso em: 9 mar. 2021.

COSTA, G. G. O. Curso de probabilidades e estatística inferencial: teoria e prática. Rio de Janeiro: Ciência Moderna, 2018.

G1. Déficit atuarial da Previdência dos servidores federais, estaduais e municipais chega a R\$ 6,5 trilhões. Economia, 5 fev. 2018. Disponível em: https://g1.globo.com/economia/blog/joao-borges/post/deficit-atuarial-da-previdencia-dos-servidores-federais-estaduais-e-municipais-chega-a-r-65-trilhoes.ghtml. Acesso em: 9 mar. 2021.

HAIR, J. F.; BLACK, W. C.; BABIN, B. J.; ANDERSON, R. E.; TATHAM, R. L. Análise multivariada de dados. 6. ed. Porto Alegre, 2009. E-book. 
JOSÉ, C. G. Gestão de recursos nos Regimes Próprios de Previdência Social (RPPS) dos municípios do estado de Santa Catarina. 2017. 79 f. Trabalho de Conclusão de Curso (Bacharelado em Ciências Contábeis) - Universidade Federal de Santa Catarina, Florianópolis, 2017. Disponível em: https://repositorio.ufsc.br/bitstream/handle/123456789/178618/ Conrado\%20Ramos\%20Jos\%C3\%A9.docx?sequence=1\&isAllowed=y. Acesso em: 11 abr. 2021.

KOURY, F. J. F. Uma função de reação para a análise da sustentabilidade do Regime Próprio de Previdência Social dos servidores do estado do Ceará no período 2003-2012. 2014. 35 f. Dissertação (Mestrado Profissional em Economia) - Universidade Federal do Ceará, Fortaleza, 2014. Disponível em: http://www.repositorio.ufc.br/bitstream/riufc/9611/1/2014_dissert_fjfkoury.pdf. Acesso em: 8 jul. 2019.

LE MONDE. Réforme des retraites: 48 questions pour comprendre le débat. 2019. Disponível em: https://www.lemonde.fr/les-decodeurs/article/2019/12/02/reforme-des-retraites-48-questions-pour-comprendre-le-debat_6021344_4355770.html. Acesso em: 9 mar. 2021.

LIMA, D. V. de; AQUINO, A. C. B. de. Resiliência financeira de fundos de regimes próprios de previdência em municípios. Rev. Cont. Fin., São Paulo, v. 30, n. 81, p. 425-445, set./dez. 2019. Disponível em: http://www. scielo.br/pdf/rcf/v30n81/pt_1808-057X-rcf-1808-057x201908810.pdf. Acesso em: 30 ago. 2019.

MAROCO, J. Análise estatística: com utilização do SPSS. 2. ed. [S. 1.]: Edições Sílabo, 2003.

MARTINS, G. A. Estatística aplicada. 3. ed. São Paulo: Atlas, 2011. 
MPS. CadPrev. Sistema de Informações dos Regimes Públicos de Previdência Social. Disponível em: https://cadprev.previdencia.gov.br/Cadprev/pages/index.xhtml. Acesso em: 20 jul. 2019.

MPS. Estatísticas e informações dos RPPS. Disponível em: https:// www.gov.br/previdencia/pt-br/assuntos/previdencia-no-servico-publico/ estatisticas-e-informacoes-dos-rpps-1/estatisticas-e-informacoes-dos-rpps. Acesso em: 10 jun. 2019.

MPS. Estatísticas e informações dos RPPS. Quantitativo de regimes por UF (Atualizado em: 16 maio 2019). Disponível em: http://sa.previdencia. gov.br/site/2020/03/Quantitativo-de-Regimes-por-UF.csv. Acesso em: 12 jun. 2019.

OLIVEIRA, R. W. B. de. Um estudo sobre a solvência financeira e atuarial dos Regimes Próprios de Previdência Social dos municípios de João Pessoa e de Campina Grande-PB. 2017. 247 f. Trabalho de Conclusão de Curso (Bacharelado em Ciências Atuariais) - Universidade Federal da Paraíba, João Pessoa, 2017. Disponível em: https://repositorio. ufpb.br/jspui/bitstream/123456789/3992/1/RWBO19042018.pdf. Acesso em: 9 mar. 2021.

PELLEGRINI, J. A situação das previdências estaduais. In: IFI, Brasília, Estudo especial, n. 9, jun. 2019. Disponível em: https://www2.senado.leg.br/bdsf/bitstream/handle/id/557965/EE_09_Previdencia_Estadual. pdf. Acesso em: 30 ago. 2019.

PONTES, P. A. A manutenção do sistema previdenciário afeta a sustentabilidade fiscal do governo? Um estudo de caso do governo do estado do Ceará. In: X CONGRESSO DE GESTÃO PÚBLICA, CONSAD, 2017, Brasília. Painel [...]. Brasília: Centro de Convenções Ulysses Guimarães, 
2017. Disponível em: http://consad.org.br/wp-content/uploads/2017/05/ Painel-44_03.pdf. Acesso em: 15 ago. 2019.

PORTELA, A.; SOUZA, B. C. N. de. A nova ofensiva ao sistema previdenciário brasileiro: um paralelo com o modelo privatista chileno. Revista Direito Estado e Sociedade, Rio de Janeiro, Ahead of print, 2020. Disponível em: https://revistades.jur.puc-rio.br/index.php/revistades/article/ view/1192. Acesso em: 9 mar. 2021.

PRATES, R. C. Métodos quantitativos à auditoria II. Curso de Especialização em Fronteiras do Conhecimento. Auditores do Século XXI. Instituto Plácido Castelo. Tribunal de Contas do Estado do Ceará (TCE-CE). Notas de aula, PowerPoint, mar. 2019. Disponível em: https://drive. google.com/file/d/1Ydkdm4k6J248A3MyXsuSjmmbJihCbsZ_view?us$\mathrm{p}=$ sharing.

RODRIGUES, R. E. A; NUNES, E. S.; SOUSA, E. P. de. A Previdência como determinante da distribuição de renda no estado do Ceará. Revista de Políticas Públicas, [s. 1.], v. 20, n. 2, p. 493-513. Disponível em: http:// www.periodicoseletronicos.ufma.br/index.php/rppublica /article/download/6347/4251. Acesso em: 15 jun. 2019.

SANTOS JUNIOR, L. C.; AZEVEDO, F. I. X. de; ANDRADE, L. M. B. Resultado atuarial e seus determinantes. In: Regimes Previdenciários e Situação Atuarial. Brasília: MF: SPREV, 2018. p. 294-316 (Coleção Previdência Social, Série Estudos. v. 36). Disponível em: https://www. gov.br/previdencia/pt-br/images/2018/06/colprev36.pdf. Acesso em: 20 jun. 2019.

SILVA, F. W. F. da. Estudo da solvência atuarial, econômica e financeira dos regimes próprios de previdência social municipais cearenses. 
2014. 88 f. Dissertação (Mestrado Profissional em Economia) - Universidade Federal do Ceará, Fortaleza, 2014. Disponível em: http://www.repositorio.ufc.br/bitstream/riufc/9618/1/2014_dissert_fwfsilva.pdf. Acesso em: 30 jun. 2019.

S-PLUS. S-Plus 4: guide to statistics. Seattle: MathSoft, Inc., 1998. 902 p. Disponível em: https://www2.stat.duke.edu/courses/Spring00/sta242/ SGUIDE.PDF. Acesso em: 2 ago. 2019.

STOLLE, Cristiane; KROENKE, Adriana; CECON, Bianca. Análise da capacidade de sustentação financeira dos regimes próprios de previdência próprio dos municípios catarinenses. Disponível em: http:// anteriores.admpg.com.br/2017/down.php?id=2791\&q=1. Acesso em: 14 ago. 2019.

TABACHNICK, B.; FIDELL, L. S. Using multivariate statistics. 3. ed. New York: Harper Collins, 1996.

TCE-PI. Nota Técnica 02/2018. Orientação aos jurisdicionados do TCE/ PI acerca de pressupostos fáticos quando da criação de Regimes Próprios de Previdência Social, de que tratam as IN no 03/17 e 09/17. Disponível em: https://www.tce.pi.gov.br/wp-content/uploads/2018/06/ Nota-T\%C3\%A9cnica-N-02-2018-1.pdf. Acesso em: 9 mar. 2021.

TCU. Relatório de Auditoria. Grupo O - Classe V. Plenário. Processo n. ${ }^{\circ}$ 008.368/2016-3. 2016. Disponível em: https://pt.scribd.com/document/355831731/008-368-2016-3-Previd-ncia-Estados-pdf. Acesso em: 30 ago. 2019.

YAŞARLAR, Y.; BAYRAKTAR, Y. Sustainability of the actuarial balance: Turkey's experience between 1972-2013. Doğuş Üniversitesi Der- 
gisi, 20 (1) 2019, 141-158. Disponível em: http://journal.dogus.edu.tr/ index.php/duj/article/view/1167. Acesso em: 9 mar. 2021.

XIE, Y.; ZHANG, X.; LV, H.; GUO, X. The new fertility policy and the actuarial balance of China urban employee basic endowment insurance fund based on stochastic mortality model. Disponível em: https://www. hindawi.com/journals/mpe/2020/3596384/. Acesso em: 9 mar. 2021. 